\title{
Stochastic Modelling And Simulation Analysis Of Confirmed Cases Of Covid 19
}

\author{
M. Haridass ${ }^{1}$ and V. Deepa ${ }^{2}$ \\ \{1'mhd.maths@psgtech.ac.in, ${ }^{2}$ vdp.maths@psgtech.ac.in\} \\ Department of Mathematics, PSG College of Technology, Coimbatore, Tamil Nadu, India
}

\begin{abstract}
Forecasting is essential to make reliable and accurate estimates of what will happen in the future in the face of uncertainty. The primary objective of forecasting is the monitoring of the continuing progress of action plans based on forecasts. COVID19 is an emerging viral infection and currently it is a major threat throughout the world. As on 7th May 2020, more than 3.5 million cases of COVID-19 and 2,50,000 deaths have been reported to WHO (World Health Organization). In this stringent situation, it is very important to forecast the cases, and it will be very much useful for healthcare department. Following this notion, we have been developing a stochastic model and then employed it for forecasting future COVID19 cases in two major countries Australia and Italy. This study explores the possibility of applying Stochastic Model to forecast the total number of new confirmed cases of COVID19, and to obtain their long run probabilities or steady state probabilities. In this article, the basic terminologies of stochastic processes and Markov Chain have been discussed. The real data were considered from WHO and analyzed the trend pertaining to the confirmed cases of the Novel Corona Virus COVID19. The Simulation study was made to justify the forecast analysis done by the stochastic model.
\end{abstract}

Keywords: Markov chain; steady state; confirmed; forecast; COVID 19, Simulation. Subject Classification: 60J22, 60J10, 65C05, 37A50.

\section{Introduction}

The current outbreak of coronavirus disease 2019 (COVID-19) has become a global crisis due to its quick and widespread over the world. Predicting the future epidemics and pandemics is much more difficult as the number of cases to be studied can be measured in one hand. In this paper, a novel stochastic model is proposed which aims to forecast the total number of new cases of COVID19.

Markov Chain was introduced by Andrei Andreevic Markov (1856 - 1922). Markov chains play a vital role in the fast emerging field stochastic processes. It also functions as an important mathematical tool in this field. Markov chains possess the most important property known as Markovian Property, which property enables simplifying predictions about scholastic by viewing the future as independent of the past, given the present state of the process. This property is referred to as "Memory less Property or Markovian Property". The Markov Chain prediction method is purely a probability forecasting method. The main principle of using Markov chain to predict is to build Markov forecasting model that predicts 
the state of an object in a certain period of time in the future by virtue of the probability vector of the initial state and state transition probability matrix.

\section{Literature Review}

Various authors have been doing forecasting analysis of the contagious virus COVID 19 through variant models. Data based Modelling and Forecasting of the novel Coronavirus analyzed by ([1]). ([3]) predicted the impact of corona virus using probability matrices and based on the secondary data as on 13th March 2020 and also studied Monte Carlo simulation. ([4]) studied the updated estimation of the risk of transmission of the novel coronavirus. Estimation of the transmission risk of the 2019-nCoV and its implication for public health interventions discussed by ([5]). ([7]) discussed Countries test tactics in 'war' against COVID-19. ([8]) discussed and surveyed from SARS-CoV to Coronavirus Disease 2019 (COVID-19).

Forecasting the novel coronavirus COVID-19 studied by ([9]). ([10]) studied forecasting of Ebola through a statistical model regression transmission model. ([11]) analyzed predictions of the epidemic development trends in South Korea, Italy, and Iran, pointing out the possible outbreaks and the corresponding control time, and tracing the earliest transmission dates of countries. ([12]) analyzed forecasting of COVID 19. ([16]) developed a discrete-time stochastic epidemic model with binomial distributions to study the transmission of the disease. Model parameters are estimated on the basis of fitting to newly reported data from January 11 to February 13, 2020 in China.

From the variant methods of simulation analysis, it is suggested that the choice of simulation is based on decision makers' requirements, type of problem and system complexity and its characteristics. A Simulation Study on Hypothetical Ebola Virus Transmission in India Using Spatiotemporal Epidemiological Modeler (STEM) discussed by ([2]). ([6]) analyzed How simulation modelling can help reduce the impact of COVID-19. Using LIWC to choose simulation approaches: A feasibility study had been done by ([13]).

([14]) analysed a Simulation Optimization Approach to Epidemic Forecasting. Real-time forecasting of infectious disease dynamics with a stochastic semi-mechanistic model discussed by ([15]). Spread of Infectious Disease Modelling and Analysis of Different Factors on Spread of Infectious Disease Based on Cellular Automata studied by ([17]). ([18]) compared discrete-event simulation and system dynamics: Users' perceptions. A Simulation-Based Study on the Comparison of Statistical and Time Series Forecasting Methods for Early Detection of Infectious Disease Outbreaks was done by ([19]).

A review of literature clearly reveals that only a very, very few authors have studied Markov models to forecast the limiting probabilities of COVID 19 in medical science with simulation. This stimulated the author to study the expertise of discrete state discrete time stochastic processes with Markovian property in forecasting the pandemic.

\section{Materials and Methods}

In this section, basic terminologies of stochastic models, Methods of Construction of forecasting model, results, sources of real data and forecasting analysis through mathematical model as well as simulation study have been discussed. 


\subsection{Basic Terminologies}

Probabilistic models prove to be much more realistic than deterministic models when it comes to studying the real world phenomena in which systems revolve randomly. Such systems are usually studied as a function of time, using mathematical models, known as stochastic models. In the following section, the basic terminologies and pre-requisites pertaining to this research article are discussed.

\subsection{Markov Processes}

Markov Processes are widely used in engineering, science, and financial models. Whenever the future state of a system depends on the present state only, not on the past state is called Markovian /Memory less property. A Stochastic Process with Markovian property is called Markov Process. The stochastic model considered for the proposed study is Discrete Time Markov chain.

\subsection{Discrete Time Markov chain}

Markov chains are used for modelling phenomena in a broad variety of academic fields such as life sciences, arts, medicine, engineering and social sciences. These chains are particularly useful to model degrees of randomness while predicting the value of an asset in the field of Financial Markets.

A Stochastic Process $\left\{X_{n} ; n=0,1,2,3,4, \ldots \ldots.\right\}$ with a finite or countably infinite state space is said to be a Markov chain, if for all $\mathrm{i}, \mathrm{j}, \mathrm{i}_{0}, \mathrm{i}_{1}, \ldots . \mathrm{i}_{\mathrm{n}-1} \in$ State space, and

$$
P\left\{X_{n+1}=j / X_{n}=i, X_{n-1}=i_{n-1}, \ldots . ., X_{0}=i_{0}\right\}=P\left\{X_{n+1}=j / X_{n}=i\right\}=P_{i j}
$$

The term ${ }^{P_{i j}}$ represents the state transition probability in one step and $P_{i j}^{n}$ represents the state transition probability in ' $n$ ' steps. The state transition probability matrix is defined as

$$
\begin{aligned}
& \left(\begin{array}{ccccc}
\mathrm{p}_{11} & \mathrm{p}_{12} & \mathrm{p}_{13} & \ldots \ldots \ldots \ldots & \mathrm{p}_{1 \mathrm{n}} \\
\mathrm{p}_{21} & \mathrm{p}_{22} & \mathrm{p}_{23} & \ldots \ldots \ldots \ldots & \mathrm{p}_{2 \mathrm{n}} \\
: & : & : & : & : \\
: & : & : & : & : \\
: & : & : & : & : \\
\mathrm{p}_{\mathrm{m} 1} & \mathrm{p}_{\mathrm{m} 2} & \mathrm{p}_{\mathrm{m} 3} & \ldots \ldots \ldots \ldots & \mathrm{p}_{\mathrm{mn}}
\end{array}\right) \text { subject to, for any row } \\
& \quad \mathrm{P}_{\mathrm{ij}} \geq 0 ; \sum_{\mathrm{j}} \mathrm{P}_{\mathrm{ij}}=1 \\
&
\end{aligned}
$$


Theorem 3.1 Let $\{\mathrm{Xn}: \mathrm{n}=0,1, \ldots\}$ be an irreducible, positive recurrent, aperiodic Markov chain with state space $\{0,1, \ldots\}$ and transition probability matrix $\mathrm{P}=(\mathrm{pij})$. Then, for each $j \geq 0, \lim _{n \rightarrow \infty} p_{i j}^{n}$ exists and is independent of i. Let $\pi_{j}=\lim _{n \rightarrow \infty} p_{i j}^{n} ; j \geq 0$ $\left(\begin{array}{c}\pi_{0} \\ \pi_{1} \\ \pi_{2} \\ : \\ :\end{array}\right)$. We have

(a)

$$
\Pi=\mathrm{P}^{\mathrm{T}} \prod \text { and } \sum_{\mathrm{j}=0}^{\infty} \pi_{\mathrm{j}}=1
$$

Furthermore, these equations determine the stationary probabilities or steady-state probabilities, $\pi_{0}, \pi_{1}, \pi_{2}, \ldots \ldots \ldots$ uniquely. (b) $\pi_{\mathrm{j}}$ is the long-run proportion of the number of transitions to state $\mathrm{j}, \mathrm{j} \geq 0$. $\frac{1}{\pi_{j}}$ (c) The expected number of transitions between two consecutive visits to state $\mathrm{j}$ is $\mathrm{j} \geq 0$

Remark: The property that the limiting probability $\pi_{\mathrm{j}}=\lim _{\mathrm{n} \rightarrow \infty} \mathrm{p}_{\mathrm{ij}}^{\mathrm{n} ; \mathrm{j} \geq 0}$ exists and is independent of the initial state $\mathrm{i}$ is called ergodicity. Any Markov chain with this property is called ergodic.

\section{Sources of data}

The data plays an important role in forecasting or predictive analysis. Forecasting methods are classified into either quantitative or qualitative. Data that is expressed in numbers and summarized using statistics to give meaningful information is referred to as quantitative data, whereas the data for description without measurement is known as qualitative data.

The primary data for this study have been collected from the World Health Organization (WHO), Coronavirus disease (COVID-19) outbreak ([20]). As these data are original and relevant to the topic of the study, the degree of accuracy is very high. Moreover, primary data is current and this can provide a realistic view of the study of the topic under consideration. The reliability of these primary data is very high since these are collected by the concerned and reliable source. In this article, we have been considered data for two countries, Australia and Italy to forecast the trend. This may be extended to several countries to forecast and analyze the behavior of COVID 19 pandemic.

\subsection{Forecasting Analysis using Markov chain for the country Australia}

In this section, the real data were considered from $\mathrm{WHO}$ (World Health Organization) for two major countries Australia and Italy for the forecasting analysis. This analysis can be applied to all other areas infected with any infectious virus. 


\subsubsection{Construction of Markov chain forecasting model}

The below mentioned process has been followed to model the study:

$>$ Construction of state space

$>$ Determination of the state probability

$>$ Construction of transition probability matrix

$>$ Calculation of state probabilities

$>$ Analysis, decision making in a stable condition

The data for total new confirmed cases affected by COVID 19 for the country Australia are considered from the period $12^{\text {th }}$ April 2020 to $30^{\text {th }}$ April 2020 (19 days), which are tabulated in table 1 . The given data are converted into exclusive class intervals and the total number of new confirmed cases (frequency) of each class interval have been identified and shown in table 2.

$$
\begin{aligned}
& \text { Let }\left\{X_{n} ; n=0,1,2,3,4, \ldots \ldots\right\} \text { be a Markov chain that represents the total number of } \\
& \text { new confirmed cases at time n. Here } X_{0}=X_{12 \text { th Apr } 2020}=51 \\
& X_{1}=X_{13 \text { th Apr } 2020}=33 \text {; and so on. }
\end{aligned}
$$

We can define the following states pertaining to the number of new confirmed cases:

$$
X_{n}=\left\{\begin{array}{l}
1, \text { if the confirmed cases less than } 20 \\
2, \text { if the confirmed cases lie in }[21,40] \\
3, \text { if the confirmed cases lie in }[41,60] \\
4, \text { if the confirmed cases more than } 60
\end{array}\right.
$$

Thus the state space of the Markov chain can be given as $\{1,2,3,4\}$. The total number of new confirmed cases for changing from one state to any of the other states is tabulated in table 3 .

The probabilities for changing to any of the other states i.e., the probability of transition from one state to any one of the other states is given by the transition probability matrix (TPM) P.

$$
\mathrm{P}=\left(\begin{array}{cccc}
0.7778 & 0.1111 & 0 & 0.1111 \\
0.6667 & 0 & 0.3333 & 0 \\
0.2 & 0.4 & 0.4 & 0 \\
0 & 0 & 1 & 0
\end{array}\right) .
$$


According to table 1, number of new confirmed cases on $30^{\text {th }}$ April 2020 fall in the interval $[0,20]$. Therefore, let us assume the initial state vector of the Markov chain be a row matrix $\left(\begin{array}{llll}1 & 0 & 0 & 0\end{array}\right)$. Thus we can obtain the state probability vector on $1^{\text {st }}$ May 2020 as

$$
\mathrm{P}^{(1)}=\left(\begin{array}{llll}
1 & 0 & 0 & 0
\end{array}\right)\left(\begin{array}{cccc}
0.7778 & 0.1111 & 0 & 0.1111 \\
0.6667 & 0 & 0.3333 & 0 \\
0.2 & 0.4 & 0.4 & 0 \\
0 & 0 & 1 & 0
\end{array}\right)=\left(\begin{array}{lllll}
0.7778 & 0.1111 & 0 & 0.1111
\end{array}\right)
$$

(1)

As the maximum transition probability of equation (1) is 0.7778 and it is connected with the 'state 1', the total number of new confirmed cases on $1^{\text {st }}$ May 2020 falls in the interval $[0$, 20]. According to the $W H O$ (World Health Organization) situation report, the total number of new confirmed cases on $1^{\text {st }}$ May 2020 is 16, which coincides with our prediction.

Now we can obtain the state probability vector on $2^{\text {nd }}$ May 2020 as

$$
\begin{aligned}
\mathrm{P}^{(2)}=\left(\begin{array}{llll}
0.7778 & 0.1111 & 0 & 0.1111
\end{array}\right)\left(\begin{array}{ccccc}
0.7778 & 0.1111 & 0 & 0.1111 \\
0.6667 & 0 & 0.3333 & 0 \\
0.2 & 0.4 & 0.4 & 0 \\
0 & 0 & 1 & 0
\end{array}\right) \\
=\left(\begin{array}{llll}
0.6790 & 0.0864 & 0.1481 & 0.0864
\end{array}\right)
\end{aligned}
$$

As the maximum transition probability the equation (2) is 0.6790 and it is connected with the 'state 1', the total number of new confirmed cases on $2^{\text {nd }}$ May 2020 falls in the interval $[0$, 20]. According to the $W H O$ (World Health Organization) situation report, the total number of new confirmed cases on $2^{\text {nd }}$ May 2020 is 5, which coincides with our prediction.

Similarly,

$$
\begin{aligned}
\mathrm{P}^{(3)} & =\left(\begin{array}{llll}
0.6790 & 0.0864 & 0.1481 & 0.0864
\end{array}\right)\left(\begin{array}{cccc}
0.7778 & 0.1111 & 0 & 0.1111 \\
0.6667 & 0 & 0.3333 & 0 \\
0.2 & 0.4 & 0.4 & 0 \\
0 & 0 & 1 & 0
\end{array}\right) \\
& =\left(\begin{array}{llll}
0.6154 & 0.1347 & 0.1745 & 0.0754
\end{array}\right)
\end{aligned}
$$

As the maximum transition probability of equation (3) is 0.6154 and it is connected with the 'state 1', the total number of new confirmed cases on $3^{\text {rd }}$ May 2020 falls in the interval $[0$, 20]. According to the $W H O$ (World Health Organization) situation report, the total number of new confirmed cases on $3^{\text {rd }}$ May 2020 is 16 , which coincides with our prediction. 
This process can be continued to forecast the total number of new confirmed cases for the future dates. The forecasted state probability vector for $4^{\text {th }}$ May 2020 is $\mathrm{P}^{(4)}=\left(\begin{array}{llll}0.6034 & 0.1382 & 0.1901 & 0.0684\end{array}\right)$. According to the WHO (World Health Organization) situation report, the total number of new confirmed cases on $4^{\text {th }}$ May 2020 is 18 , which coincides with our prediction.

\subsubsection{Stability Analysis and forecasting using Markov chain}

Clearly the Markov chain $\left\{X_{n} ; n=0,1,2,3,4, \ldots \ldots\right\}$ is an irreducible, aperiodic and recurrent. Since it is a finite state Markov chain, it also happens to be a positive recurrent. Let $\pi_{1}, \pi_{2}, \pi_{3}$, and $\pi_{4}$ be the proportion of the periods or limiting probabilities or steady state probabilities of the total number of new confirmed cases to be fallen in the interval $[0,20],[21,40],[41,60]$ and more than 60 respectively.

By the theorem 3.1, $\left(\begin{array}{l}\pi_{1} \\ \pi_{2} \\ \pi_{3} \\ \pi_{4}\end{array}\right)=\left(\begin{array}{cccc}0.7778 & 0.1111 & 0 & 0.1111 \\ 0.6667 & 0 & 0.3333 & 0 \\ 0.2 & 0.4 & 0.4 & 0 \\ 0 & 0 & 1 & 0\end{array}\right)^{\mathrm{T}}\left(\begin{array}{l}\pi_{1} \\ \pi_{2} \\ \pi_{3} \\ \pi_{4}\end{array}\right)$ and $\pi_{1}+\pi_{2}+\pi_{3}+\pi_{4}=1$

(4)

$$
\begin{aligned}
&\left(\begin{array}{l}
\pi_{1} \\
\pi_{2} \\
\pi_{3} \\
\pi_{4}
\end{array}\right)=\left(\begin{array}{cccc}
0.7778 & 0.6667 & 0.2 & 0 \\
0.1111 & 0 & 0.4 & 0 \\
0 & 0.3333 & 0.4 & 1 \\
0.1111 & 0 & 0 & 0
\end{array}\right)\left(\begin{array}{l}
\pi_{1} \\
\pi_{2} \\
\pi_{3} \\
\pi_{4}
\end{array}\right) \\
& 0.7778 \pi_{1}+0.6667 \pi_{2}+0.2 \pi_{3}=\pi_{1} \\
& 0.1111 \pi_{1}+0.40 \pi_{3}=\pi_{2} \\
& 0.3333 \pi_{2}+0.40 \pi_{3}+\pi_{4}=\pi_{3} \\
& 0.1111 \pi_{1}=\pi_{4} \\
& \pi_{1}+\pi_{2}+\pi_{3}+\pi_{4}=1
\end{aligned}
$$


The above system of equations can be solved numerically upon which we arrive at the following values: $\pi_{1}=0.6000 ; \pi_{2}=0.1428 ; \pi_{3}=0.1905$ and $\pi_{4}=0.0667$ (5)

Hence we can conclude that as $n \rightarrow \infty$, the probabilities will converge to a steady state probability. Since the maximum of the steady state probabilities is 0.6 , implying that $60.00 \%$ of the period (number of days) is likely to the total number of new confirmed cases will fall in the interval $[0,20]$. Thus the forecast says that the total number of new confirmed cases in future will be a value in the interval $[0,20]$.

\subsection{Forecasting and Stability Analysis using Markov chain for the country Italy}

The data for total new confirmed cases affected by COVID 19 for the country Italy are considered from the period 10th April 2020 to $3^{\text {rd }}$ May 2020 (24 days) which are tabulated in table 4. The given data are converted into class intervals and the total number of new confirmed cases (frequency) of each class interval have been identified and shown in table 5 .

For these intervals we can define the following states pertaining to the number of new confirmed cases:

$$
X_{n}=\left\{\begin{array}{l}
1, \text { if the confirmed cases less than } 2000 \\
2, \text { if the confirmed cases lie in }[2001,2500] \\
3, \text { if the confirmed cases lie in }[2501,3000] \\
4, \text { if the confirmed cases lie in }[3001,3500] \\
5, \text { if the confirmed cases lie in }[3501,4000] \\
6, \text { if the confirmed cases more than } 4001
\end{array}\right.
$$

Thus the state space of the Markov chain can be given as $\{1,2,3,4,5,6\}$. The total number of new confirmed cases for changing from one state to any of the other states is tabulated in table 6 .

The probabilities for changing to any of the other states i.e., the probability of transition from one state to any one of the other states is given by the transition probability matrix (TPM) P.

$$
\mathrm{P}=\left(\begin{array}{cccccc}
0.6667 & 0.3333 & 0 & 0 & 0 & 0 \\
0.4 & 0.4 & 0.2 & 0 & 0 & 0 \\
0 & 0 & 0.25 & 0.5 & 0.25 & 0 \\
0 & 0.2 & 0.4 & 0.4 & 0 & 0 \\
0 & 0 & 0 & 0.5 & 0 & 0.5 \\
0 & 0 & 0 & 0.33 & 0.33 & 0.33
\end{array}\right)
$$


According to table 4, On $3^{\text {rd }}$ May 2020, number of new confirmed cases fall in the interval $[0,2000]$. Therefore, let us assume the initial state vector of the Markov chain be a row matrix $\left(\begin{array}{llllll}1 & 0 & 0 & 0 & 0 & 0\end{array}\right)$. The state probability vectors as well as long run probabilities have been obtained and tabulated in the table 7 .

Hence we can conclude that as $n \rightarrow \infty$, the probabilities will converge to a steady state probability. Since the maximum of the steady state probabilities is 0.269 , implying that $26.90 \%$ of the period (number of days) is likely to the total number of new confirmed cases will fall in the interval [0,2000]. Thus the forecast says that the total number of new confirmed cases in future will be a value in the interval $[0,2000]$. Thus the number of new confirmed cases predicted by the theorem is consistent with the actual situation. Moreover, the above said theorem can be applied subject to the condition that the identifying Markov chain should be Ergodic. The class intervals can be changed accordingly to achieve this Ergodic Markov chain.

\section{Simulation Analysis}

In this article, the simulation analysis model has been done to study the forecast the number of new confirmed cases of COVID19. The Monte Carlo simulation concept was applied and implemented for measuring and analyzing the forecast of the number of new confirmed cases of COVID19 pandemic.

Simulation analysis of confirmed cases for the country Italy has been done in the three sets of random numbers. The results have been tabulated in table 8 and figure 2. The average the simulated probability for random number set I am 0.5 , and 0.4663 and 0.5009 are the simulated probabilities for the random number sets II and III respectively. It depicts that $50 \%$ of the period (number of days) is likely to the total number of new confirmed cases will fall in the interval $[0,2000]$. Thus the forecast says that the total number of new confirmed cases in future will be a value in the interval $[0,2000]$ which coincides with the forecast analysis done by the stochastic model.

\section{Conclusion}

The preceding paragraphs discussed the, applications of Discrete Time Markov Chain in the emerging field forecasting, and achieved relatively good results pertaining to COVID 19 pandemic. Their long run or steady state probabilities have also been obtained. To forecast the total number of new confirmed cases of the Novel Corona Virus COVID 19, the real data from WHO (World Health Organization) have been considered and analyzed. Simulation analysis was made to justify the forecast analysis done by the stochastic model. However, the Markov chain prediction method is a probability forecasting method, the predicted results are simply expressed the probability of a certain state of the total number of new confirmed cases in the future, rather than being in an absolute state.

\section{Acknowledgment}

The author would be grateful to thank the World Health Organization (WHO), which helped in bringing the paper to its present form. 
Table 1 Dates (Vs) Total number of confirmed new cases for Australia

\begin{tabular}{|c|c|c|c|c|c|c|c|c|c|c|c|c|c|c|c|c|c|c|c|}
\hline \multirow{2}{*}{$\begin{array}{l}\text { Country } \\
\text { Australia }\end{array}$} & \multicolumn{19}{|c|}{ Dates : From 12/04/2020 to 30/04/2020 (19 days) } \\
\hline & 12 & 13 & 14 & 15 & 16 & 17 & 18 & 19 & 20 & 21 & 22 & 23 & 24 & 25 & 26 & 27 & 28 & 29 & 30 \\
\hline $\begin{array}{l}\text { Total } \\
\text { confirmed } \\
\text { new cases }\end{array}$ & 51 & 33 & 44 & 50 & 42 & 10 & 65 & 53 & 26 & 13 & 22 & 7 & 13 & 20 & 16 & 10 & 12 & 13 & 8 \\
\hline
\end{tabular}

Table 2 Class Intervals (Vs) Number of confirmed new cases (Frequency) for Australia

\begin{tabular}{|l|l|l|l|l|}
\hline Country Australia & $\begin{array}{l}\text { Less than or equal to } \\
\mathbf{2 0}\end{array}$ & $\begin{array}{l}\mathbf{2 1 -} \\
\mathbf{4 0}\end{array}$ & $\mathbf{4 1 - 6 0}$ & $\begin{array}{l}\text { Greater than or equal to } \\
\mathbf{6 0}\end{array}$ \\
\hline Frequency & 10 & 3 & 5 & 1 \\
\hline State & $\mathrm{S} 1$ & $\mathrm{~S} 2$ & $\mathrm{~S} 3$ & $\mathrm{~S} 4$ \\
\hline
\end{tabular}

Table 3 Transition from one state to another state (Vs) Frequency for Australia

\begin{tabular}{|l|l|l|l|l|}
\hline State & S1 & S2 & S3 & S4 \\
\hline S1 & 7 & 1 & 0 & 1 \\
\hline S2 & 2 & 0 & 1 & 0 \\
\hline S3 & 1 & 2 & 2 & 0 \\
\hline S4 & 0 & 0 & 1 & 0 \\
\hline
\end{tabular}

Table 4 Dates (Vs) Total number of confirmed new cases for Italy

\begin{tabular}{|c|c|c|c|c|c|c|c|c|c|c|c|c|c|c|c|c|c|c|c|c|c|c|c|c|}
\hline \multirow{2}{*}{$\begin{array}{c}\text { Country } \\
\text { Italy }\end{array}$} & 10 & 11 & 12 & 13 & 14 & 15 & 16 & 17 & 18 & 19 & 20 & 21 & 22 & 23 & 24 & 25 & 26 & 27 & 28 & 29 & 30 & 1 & 2 & 3 \\
\hline $\begin{array}{r}\text { Confirmed } \\
\text { new cases }\end{array}$ & 4204 & 3951 & 4694 & 4092 & 3153 & 2972 & 2667 & 3786 & 3493 & 3491 & 3047 & 2256 & 2729 & 3370 & 2646 & 3021 & 2357 & 2324 & 1739 & 2091 & 2086 & 1872 & 1965 & 1900 \\
\hline
\end{tabular}

Table 5 Class Intervals (Vs) Number of confirmed new cases (Frequency) for Italy

\begin{tabular}{|l|l|l|l|l|l|l|}
\hline $\begin{array}{l}\text { Country } \\
\text { Italy }\end{array}$ & $\mathbf{2 0 0 0}$ & $\begin{array}{l}\mathbf{2 0 0 1 -} \\
\mathbf{2 5 0 0}\end{array}$ & $\begin{array}{l}\mathbf{2 5 0 1 -} \\
\mathbf{3 0 0 0}\end{array}$ & $\begin{array}{l}\mathbf{3 0 0 1 -} \\
\mathbf{3 5 0 0}\end{array}$ & $\begin{array}{l}\mathbf{3 5 0 1 -} \\
\mathbf{4 0 0 0}\end{array}$ & $>\mathbf{4 0 0 1}$ \\
\hline Frequency & 4 & 5 & 4 & 6 & 2 & 3 \\
\hline State & $\mathrm{S} 1$ & $\mathrm{~S} 2$ & $\mathrm{~S} 3$ & $\mathrm{~S} 4$ & $\mathrm{~S} 5$ & $\mathrm{~S} 6$ \\
\hline
\end{tabular}

Table 6 Transition from one state to another state (Vs) Frequency for Italy

\begin{tabular}{|l|l|l|l|l|l|l|}
\hline State & S1 & S2 & S3 & S4 & S5 & S6 \\
\hline S1 & 2 & 1 & 0 & 0 & 0 & 0 \\
\hline S2 & 2 & 2 & 1 & 0 & 0 & 0 \\
\hline S3 & 0 & 0 & 1 & 2 & 1 & 0 \\
\hline S4 & 0 & 1 & 2 & 2 & 0 & 0 \\
\hline S5 & 0 & 0 & 0 & 1 & 0 & 1 \\
\hline S6 & 0 & 0 & 0 & 1 & 1 & 1 \\
\hline
\end{tabular}



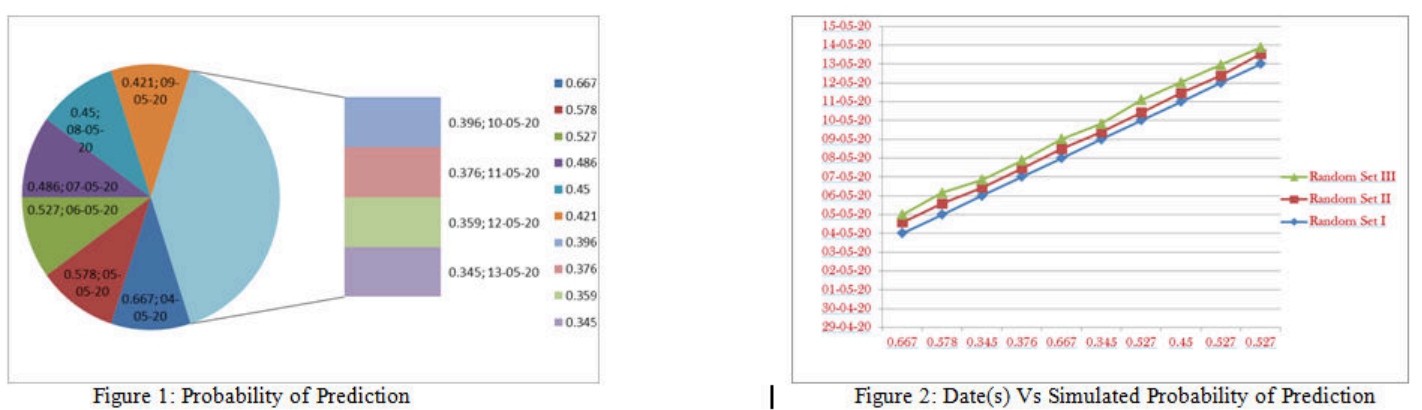

Table 7 Forecasting analysis for the country Italy

\begin{tabular}{|c|c|c|c|c|c|c|c|}
\hline Date & State vector & $\begin{array}{c}\text { After one transition, state transition } \\
\text { probability vector }\end{array}$ & $\begin{array}{c}\text { Max } \\
\text { probabilit } \\
y\end{array}$ & $\begin{array}{l}\text { correspondi } \\
\text { ng state }\end{array}$ & \begin{tabular}{|c|} 
Interval \\
predicted for \\
new confirmed \\
cases \\
\end{tabular} & $\begin{array}{l}\text { WHO } \\
\text { Situation } \\
\text { report }\end{array}$ & Forecasting \\
\hline $04 / 05 / 2020$ & $(1,0,0,0,0,0)-$ Initial vector & $(0.667,0.333,0,0,0,0)$ & 0.667 & state ' 1 " & {$[0,2000]$} & 1389 & $\begin{array}{l}\begin{array}{l}\text { Coincides with } \\
\text { prediction }\end{array} \\
\end{array}$ \\
\hline $05 / 05 / 2020$ & $(0.6667,0.3333,0,0,0,0)$ & $(0.578,0.356,0.067,0,0,0)$ & 0.578 & state ' 1 ' & {$[0,2000]$} & 1221 & $\begin{array}{l}\text { Coincides with } \\
\text { prediction }\end{array}$ \\
\hline $06 / 05 / 2020$ & $(0.578,0.356,0.067,0,0,0)$ & $(0.527,0.335,0.088,0.033,0.017,0)$ & 0.527 & state ' 1 ' & {$[0,2000]$} & 1075 & $\begin{array}{l}\text { Coincides with } \\
\text { prediction }\end{array}$ \\
\hline $07 / 05 / 2020$ & $(0.527,0.335,0.088,0.033,0.017,0)$ & $\begin{array}{l}(0.486,0.316,0.102,0.066,0.022, \\
0.009)\end{array}$ & 0.486 & state ' 1 ' & {$[0,2000]$} & 1444 & $\begin{array}{l}\text { Coincides with } \\
\text { prediction }\end{array}$ \\
\hline $08 / 05 / 2020$ & $\begin{array}{l}(0.486,0.316,0.102,0.066,0.022, \\
0.009)\end{array}$ & $\begin{array}{l}(0.450,0.302,0.115,0.091,0.028, \\
0.014)\end{array}$ & 0.450 & state ' 1 ' & {$[0,2000]$} & 1401 & $\begin{array}{l}\text { Coincides with } \\
\text { prediction }\end{array}$ \\
\hline $09 / 05 / 2020$ & $\begin{array}{l}(0.450,0.302,0.115,0.091,0.028, \\
0.014)\end{array}$ & $\begin{array}{l}(0.421,0.289,0.126,0.113,0.033, \\
0.019)\end{array}$ & 0.421 & state ' 1 ' & {$[0,2000]$} & 1327 & $\begin{array}{l}\text { Coincides with } \\
\text { prediction }\end{array}$ \\
\hline $10 / 05 / 2020$ & $\begin{array}{l}(0.421,0.289,0.126,0.113,0.033, \\
0.019)\end{array}$ & $\begin{array}{l}(0.396,0.279,0.135,0.131,0.038, \\
0.023)\end{array}$ & 0.396 & state ' 1 ' & {$[0,2000]$} & 1083 & $\begin{array}{l}\text { Coincides with } \\
\text { prediction }\end{array}$ \\
\hline $11 / 05 / 2020$ & $\begin{array}{l}(0.396,0.279,0.135,0.131,0.038, \\
0.023)\end{array}$ & $\begin{array}{l}(0.376,0.270,0.142,0.147,0.041, \\
0.027)\end{array}$ & 0.376 & state ' 1 ' & {$[0,2000]$} & 802 & $\begin{array}{l}\text { Coincides with } \\
\text { prediction }\end{array}$ \\
\hline $12 / 05 / 2020$ & $\begin{array}{l}(0.376,0.270,0.142,0.147,0.041, \\
0.027)\end{array}$ & $\begin{array}{l}(0.359,0.263,0.148,0.159,0.045, \\
0.030)\end{array}$ & 0.359 & state ' 1 ' & {$[0,2000]$} & 744 & $\begin{array}{l}\text { Coincides with } \\
\text { prediction }\end{array}$ \\
\hline $13 / 05 / 2020$ & $\begin{array}{l}(0.359,0.263,0.148,0.159,0.045, \\
0.030)\end{array}$ & $\begin{array}{l}(0.345,0.257,0.153,0.170,0.047, \\
0.032)\end{array}$ & 0.345 & state ' 1 ' & {$[0,2000]$} & 1402 & $\begin{array}{l}\text { Coincides with } \\
\text { prediction }\end{array}$ \\
\hline$:$ & : & : & : & $:$ & $:$ & $:$ & : \\
\hline 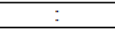 & 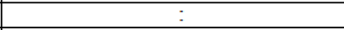 & 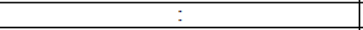 & 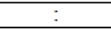 & 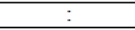 & 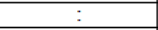 & $:$ & 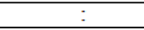 \\
\hline$:$ & $:$ & $:$ & $:$ & $:$ & $:$ & $:$ & $:$ \\
\hline & $:$ & : & $:$ & $:$ & $:$ & $:$ & : \\
\hline $\begin{array}{l}\text { When } \\
n \rightarrow \infty\end{array}$ & & $\begin{array}{l}(0.269,0.224,0.179,0.224,0.060, \\
0.045)\end{array}$ & 0.269 & state ' 1 ' & {$[0,2000]$} & $\mathrm{x}$ & $\begin{array}{l}\text { Coincides with } \\
\text { prediction }\end{array}$ \\
\hline
\end{tabular}

Table 8 Simulation analysis of confirmed cases of the country Italy

\begin{tabular}{|c|c|c|c|c|c|c|c|c|c|c|}
\hline Date & $\begin{array}{l}\text { Maximum } \\
\text { probability }\end{array}$ & $\begin{array}{l}\text { probability } \\
\text { (max } \\
\text { probability) }\end{array}$ & $\begin{array}{l}\text { Cumulative } \\
\text { probability }\end{array}$ & Tag no & $\begin{array}{c}\text { Random } \\
\text { number } \\
\text { set I }\end{array}$ & $\begin{array}{c}\text { Simulated } \\
\text { probability }\end{array}$ & $\begin{array}{c}\text { Random } \\
\text { number } \\
\text { set II }\end{array}$ & $\begin{array}{c}\text { Simulated } \\
\text { probability }\end{array}$ & $\begin{array}{c}\text { Random } \\
\text { number } \\
\text { set III }\end{array}$ & $\begin{array}{l}\text { Simulated } \\
\text { probability }\end{array}$ \\
\hline $04 / 05 / 2020$ & 0.667 & 0.145 & 0.145 & $0-13$ & 65 & 0.421 & 24 & 0.578 & 10 & 0.667 \\
\hline $05 / 05 / 2020$ & 0.578 & 0.126 & 0.27 & $14-26$ & 24 & 0.578 & 20 & 0.578 & 19 & 0.578 \\
\hline $06 / 05 / 2020$ & 0.527 & 0.114 & 0.385 & $27-37$ & 63 & 0.421 & 63 & 0.421 & 96 & 0.345 \\
\hline $07 / 05 / 2020$ & 0.486 & 0.106 & 0.49 & $38-48$ & 60 & 0.421 & 57 & 0.45 & 79 & 0.376 \\
\hline $08 / 05 / 2020$ & 0.450 & 0.098 & 0.588 & $49-58$ & 27 & 0.527 & 45 & 0.486 & 12 & 0.667 \\
\hline $09 / 05 / 2020$ & 0.421 & 0.091 & 0.679 & $59-67$ & 58 & 0.45 & 79 & 0.376 & 95 & 0.345 \\
\hline $10 / 05 / 2020$ & 0.396 & 0.086 & 0.765 & $68-76$ & 0 & 0.667 & 60 & 0.421 & 28 & 0.527 \\
\hline $11 / 05 / 2020$ & 0.376 & 0.082 & 0.847 & $77-84$ & 17 & 0.578 & 57 & 0.45 & 49 & 0.45 \\
\hline $12 / 05 / 2020$ & 0.359 & 0.078 & 0.925 & $85-92$ & 15 & 0.578 & 83 & 0.376 & 27 & 0.527 \\
\hline $13 / 05 / 2020$ & 0.345 & 0.075 & 1 & $93-99$ & 89 & 0.359 & 34 & 0.527 & 31 & 0.527 \\
\hline \multirow[t]{2}{*}{ Tot } & 4.605 & & & & & 5.000 & & 4.663 & & 5.009 \\
\hline & & & & & Ave & 0.5000 & & 0.4663 & & 0.5009 \\
\hline
\end{tabular}

\section{References}


[1] C Anastassopoulou, L. Russo, A. Tsakris, and C. Siettos, Data-Based Analysis, Modelling and Forecasting of the novel Coronavirus (2019-nCoV) outbreak. medRxiv. (2020), doi: https://doi.org/10.1101/2020.02.11.20022186

[2] Arkaprabha Sau, A Simulation Study on Hypothetical Ebola Virus Transmission in India Using Spatiotemporal Epidemiological Modeler (STEM): A Way towards Precision Public Health, Hindawi Journal of Environmental and Public Health (2017), 2017: 8 pages. https://doi.org/10.1155/2017/7602301

[3] Arumugam Raju and Raji Rajathi, A Markov Model for Prediction of Corona Virus COVID-19 in India-A Statistical Study, Journal of Xidian University 14 (2020), 1422-1426. https://doi.org/10.37896/jxu14.4/164

[4] N. Biao Tang, Q. Bragazzi, S. Li, Y. Tang, J. Xiao, and Wu, An updated estimation of the risk of transmission of the novel coronavirus (2019-nCov), Infect. Disease Model 5 (2020), 248-255. https://doi.org/10.1016/j.idm.2020.02.001

[5] Biao Tang, X. Wang, Q. Li, N. L. Bragazzi, S. Tang, Y. Xiao, and J. Wu, Estimation of the transmission risk of the $2019-\mathrm{nCoV}$ and its implication for public health interventions, J. Clin. Med. 9 (2020), 462. doi: 10.3390/jcm9020462

[6] S.M. Christine Currie, W. John Fowler, Kathy Kotiadis, Thomas Monks, Bhakti Stephan Onggo, A. Duncan, Robertson, and A. Antuela Tako, How simulation modelling can help reduce the impact of COVID-19, Journal of Simulation (2020) [15 Apr 2020]. https://doi.org/10.1080/17477778.2020.1751570

[7] J. Cohen, and K. Kupferschmidt, Countries test tactics in 'war' against COVID-19. Science. 2020;367:1287-1288. doi: 10.1126/science.367.6484.

[8] M.K. Daga, N. Kumar, J. Aarthi, G. Mawari, S. Garg, and I. Rohatgi, From SARS-CoV to Coronavirus Disease 2019 (COVID-19)-A Brief Review, Journal of Advanced Research in Medicine 6 (2019), 1-9.

[9] Fotios Petropoulos, and Spyros Makridakis, Forecasting the novel coronavirus COVID-19, PLoS One 15 (2020), 231-236. doi.org/10.1371/journal.pone.0231236

[10] Jason Asher, Forecasting Ebola with a regression transmission model. Epidemics 22 (2018), 50-55. https://doi.org/10.1016/j.epidem.2017.02.009

[11] Lixiang Li, Zihang Yang, Zhongkai Dang, Cui Meng, Jingze Huang, Haotian Meng, Deyu Wang, Guanhua Chen, Jiaxuan Zhang, Haipeng Peng and Yiming Shao, Propagation analysis and prediction of the COVID-19, Infectious Disease Modelling 5 (2020), 282-292.

[12] Matjaž Perc, Nina Gorišek Miksić, Mitja Slavinec, and Andraž Stožer, Forecasting COVID-19, Front. Phys. (2020) [08 April 2020]. https://doi.org/10.3389/fphy.2020.00127.

[13] R. McHaney, A. Tako, and S. Robinson, Using LIWC to choose simulation approaches: A feasibility study, Decision Support Systems 111 ( 2018), 11-12. https:// doi.org/10.1016/j.dss.2018.04.002

[14] EO. Nsoesie, RJ. Beckman, S. Shashaani, KS. Nagaraj, and MV. Marathe, A Simulation Optimization Approach to Epidemic Forecasting, PLoS ONE 8 (2013), 67164. https://doi.org/10.1371/journal.pone.0067164

[15] Sebastian Funk, Anton Camacho, J. Adam Kucharski, Rosalind M. Eggo, and W. John Edmunds, Real-time forecasting of infectious disease dynamics with a stochastic semi-mechanistic model, Epidemics 22 (2018), 56 - 61.https://doi.org/10.1016/j.epidem.2016.11.003

[16] Sha He, Sanyi Tang, and Libin Rong, A discrete stochastic model of the COVID-19 outbreak: Forecast and control, Mathematical Biosciences and Engineering 17 (2020), 2792-2804. doi: $10.3934 / \mathrm{mbe} .2020152$

[17] Sheng Bin, Gengxin Sun, and Chih-Cheng Chen, Spread of Infectious Disease Modeling and Analysis of Different Factors on Spread of Infectious Disease Based on Cellular Automata, Int J Environ Res Public Health 16 (2019), 4683. doi. 10.3390/ijerph16234683

[18] A.A. Tako, and S. Robinson, Comparing discrete-event simulation and system dynamics: Users' perceptions, Journal of the Operational Research Society 60 (2009), 296-312. https://doi.org/10.1057/palgrave.jors.2602566 
[19] E. Yang, HW. Park, YH. Choi, J. Kim , L. Munkhdalai, I. Musa, and KH. Ryu, A SimulationBased Study on the Comparison of Statistical and Time Series Forecasting Methods for Early Detection of Infectious Disease Outbreaks, Int J Environ Res Public Health 15 (2018), 966. doi: 10.3390/ijerph15050966

[20] World Health Organization, Coronavirus disease (COVID-19) outbreak. https://www.who.int/emergencies/diseases/novel-coronavirus-2019/situation-reports/ 